\title{
Design and Development of Market Demand Analysis System for Passenger Aircraft
}

\author{
Peiwen Zhang * \\ College of Airport Engineering and Transportation \\ Management \\ Civil Aviation Flight University of China \\ Guanghan, China \\ peiwen_zhang@163.com \\ *Corresponding Author \\ Ganxiang Huang \\ College of Airport Engineering and Transportation \\ Management \\ Civil Aviation Flight University of China \\ Guanghan, China \\ hgx312@139.com
}

\author{
Hong Sun \\ College of Airport Engineering and Transportation \\ Management \\ Civil Aviation Flight University of China \\ Guanghan, China \\ hanksun@263.net
}

\begin{abstract}
In accordance with the characteristics of passenger aircraft market demand analysis, this paper constructs a demand analysis model which, at first, establishes 'typical route' through route market segmentation, and then determines the market plan of passenger aircraft based on the 'typical route' transportation capacity configuration model. Furthermore, by using net frame and MATLAB, this paper develops a demand analysis system for civil aviation aircraft. The system is efficient, stable, and easy to operate, reduces the complexity of passenger aircraft market analysis, and thus promotes the analyzing efficiency.
\end{abstract}

Keywords- Air transportation; civil airplane market demand;.NET technology; MATLAB

\section{INTRODUCTION}

The precondition of designing a product is to correctly define its market demands. In aviation industry, aircraft manufacturers put utmost interests in the types of the aircraft the market demands in terms of its seat levels and endurance, and the scale of the demands. Under these considerations, the correct strategy of manufacturing civil aircrafts is carried out. In 1960 s, by indepth analys is of market demands for civil aircrafts, Boeing foresaw the large market demands for 400-seats jetliners in intercontinental commuting, and thus initiated the development of Boeing 747 which sooner became the dominance in global long-distance jumbo jet market. Therefore, Deeping the analysis of market demands for civil aircraft has great significance for manufactures to make correct civil aircraft developing strategy[1].

At present, domestic research on civil aircraft market demands just began, while other aircraft manufacturesAirbus, Boeing as representatives - have all developed their own market demands analysis methods, issue global market demands reports regularly[2-4], but all the details about the analysis methods are confidential, and related articles are neverpublicly printed.

To sum up, finding the market predicting methods and improving the automatic level have become an immanent question seeking for answers. Therefore, finding a practical market demand analysis procedure and methods, and developing a feasible data analysis system can not only promote the quality and efficiency of demand analysis, but also decrease the possibilities of incorrect analysis results caused by human errors.

\section{SYSTEM STRUCTURE}

Based on a simulating environment of aviation transportation market in specific regions, the system gives a comprehensive consideration on the limits of regional airport capacity to each flight frequency, limits of flight human resources supply to the flight utilization efficiency, aims at minimize the fleet operating costs, seeks for the optimized matching strategy of aircraft types and flight, and evaluates the demands of aviation transportation market of specific regions for different types and levels of aircrafts. The overall function of this system is shown in Fig. 1. The system is composed of 6 modules, namely document, basic data, market environment, demands analysis, system management and help, among which basic data, market environment and demands analysis are the core parts. 


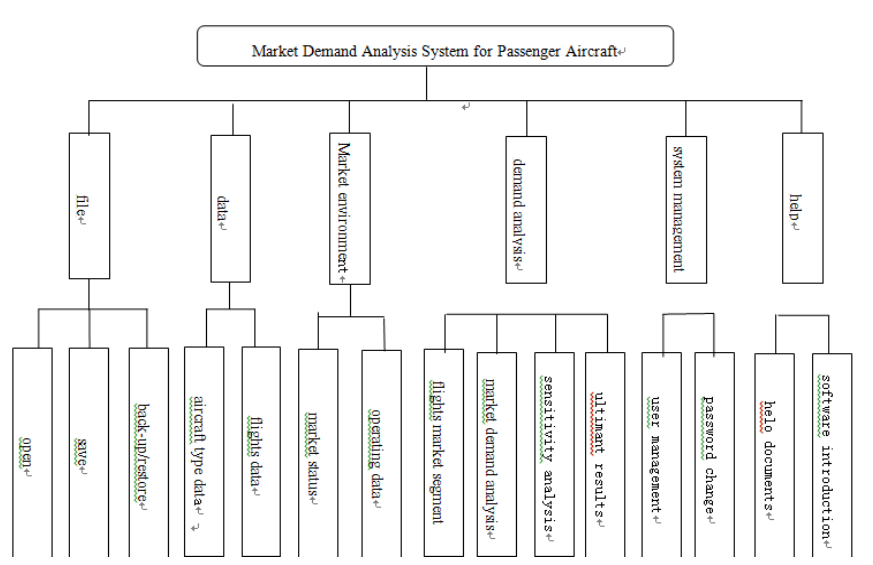

Figure 1. System's overall structure

\section{MATHEMATIC MODEL AND METHOD}

Since flights in specific regions are numerous, this paper divides specific regions into many market segments, and only one typical flight is selected from each segment to represent that market. Then the philosophy mentioned in reference book [5] is adapted to evaluated the reasonable demands for different types and levels of aircrafts in specific regional aviation transportation market.

\section{A. Flight Market Segmenting Method}

$\mathrm{K}$-means has the following features: each and every cluster is compact on its own, but separate in between. Therefore, if take reference from K-means algorithm, the flight market segmenting would be designed as follows: Firstly select 8 index as the segmenting parameters, namely the flight distance, average frequency, seat number, average passenger capacity, revenue per flight, average ticket price, revenue per seat per kilo meter and revenue per passenger per kilometer[]; then randomly select $\mathrm{K}$ flights out of $\mathrm{N}$ flights as initial cluster center. And those lefted flights would be allocated to the most similar cluster according to its similarity (distance) to the cluster center. And then calculate the cluster centers gained by each flights. This process will be repeated until standard measure function begins to converge. The mean square error is adapted as standard measure function.

The detailed procedure is as follows:

1) randomly select $k$ cluster centroid points as $u_{1}, u_{2}, \cdots, u_{k} \in R^{n}$;

2) allocate each flight $i$ to the most similar cluster according to the minimum distance rules. the calculating format is the following NO. (1) format.

$$
c^{(i)}:=\arg \min _{j}\left\|x^{(i)}-u_{j}\right\|
$$

3) calculate the average value of each cluster sample as the new clustercenter

$$
u_{j}:=\frac{\sum_{i=1}^{m} 1\left\{c^{(i)}=j\right\} x^{(i)}}{\sum_{i=1}^{m} 1\left\{c^{(i)}=j\right\}}
$$

4) repeat step 2) and step 3) until the square error and criterion function no longer change.

$$
E=\sum_{j=1}^{k} \sum_{i=1}^{m} 1\left\{c^{(i)}=j\right\}\left\|x^{(i)}-u_{j}\right\|^{2}
$$

5) finished, and the number of market segments is $k$.
Among the parameters, the flight sample is $\left\{x^{(1)}, \cdots, x^{(m)}\right\}$,each $x^{(i)} \in R$; the given number of cluster is $\mathrm{k}$; $c^{(i)}$ stands for the most similar cluster among k clusters that flight $\mathrm{i}$ is allocated to, $c^{(i)}$ is one centroid from 1 to $\mathrm{k} ; u_{j}$ stands for the conjecture of sample center in the same cluster.

B. Civil Aircraft Market Demands Analysis Model Based on Transportation Capacity Optimizing Ollocation

Given there is selectable "typical types" aggregation I, typical route aggregation of each market segments $\mathrm{J}$, aiming at minimizing fleet operation costs, capable of satisfying each typical route' $s$ minimum passenger number limits and maximum flight frequency limits, An integer programming model of optimal match of aircraft types and routes can be constructed as follow:

1) Targeting at minimize fleet overall operating costs can be described as:

$$
\min \sum_{i \in I} \sum_{j \in J} x_{i j} \times\left(c d_{i j}+\beta_{i j} \times c p\right)
$$

2) Constraint conditions: 1 . the total flight number of each flight during scheduled period (month) should be no more than the maximum flight number allowed in that flight, see (5);2. the total passenger number of each flight should be no less than the estimated passenger number of that flight, see (6);3. the total flight time of all aircraft types should be no more than the actual practical flight time the flight crew can provide, see (7).

$$
\begin{aligned}
& \sum_{i \in I} x_{i j} \leq f_{j}, \forall j \in J \\
& \sum_{i \in I} x_{i j} \times s_{i} \times l f_{i j} \geq d_{j}, \forall j \in J \\
& \sum_{i \in I} \sum_{j \in J} x_{i j} \times t e_{i j} \leq t c \\
& x_{i j} i s \quad \text { Interger, } \forall i \in I ; \forall j \in J
\end{aligned}
$$

For detailed explanation of the model and parameters, see reference [5].

By solving the above integer programming question, the optimal match between aircraft types and routes can be obtained, which, combining with the utilization ratio $t f_{i}$ of each type, will help to define the required aircraft number of each aircraft types.

$$
N_{i}=\left\lceil\frac{\sum_{j=1}^{n} x_{i j} \times t e_{i j}}{t f_{i}}\right\rceil
$$

\section{SYSTEM DESIGN}

This system is developed on platform Visual Studio 2010, the simulated market segmenting and picturing of the system is developed under MATL AB7.7, the simulated model of civil aircraft market demands analysis is developed under Lingo API. the system overall structure adapts $\mathrm{C} / \mathrm{S}$ structure, consisting of 6 modules. the client main interface is shown in Fig. 2. 


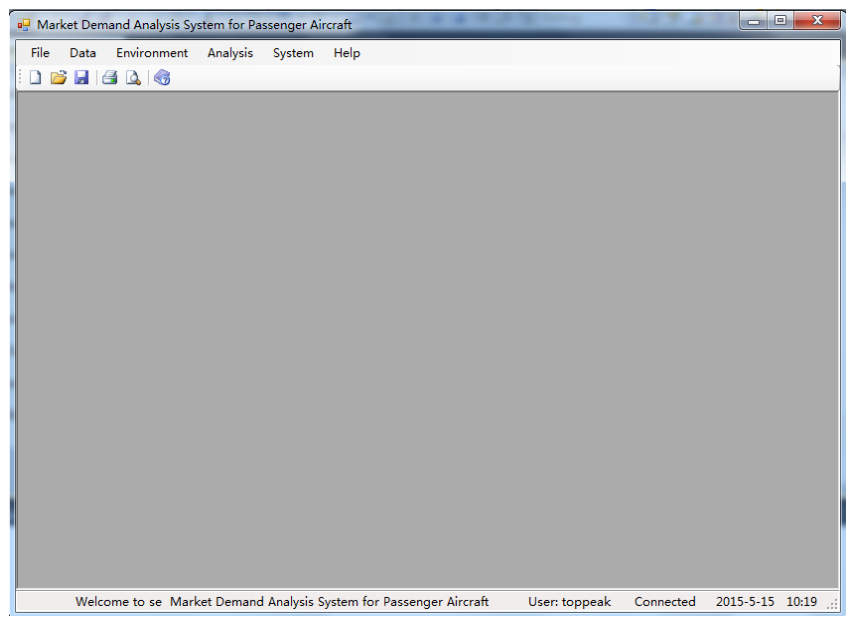

Figure 2. Client main interface

The Document module is used for opening and saving data documents and data templates, backing-up and restoring database. the data module is used for system maintenance such as add, delete or modify the aircraft types data, flights information data, market status data and operating data. for this module, different user levels have different authorities.

System management module is used for user management, authority management and password modification, the administrator can add and delete users, and change user's password. help module is used for providing resolution advisory and relevant explanation of the system. the above 4 modules can be found in many systems, and normally share the same function, due to space constraints, the design and realization of the 4 modules will not be described in detail. this section mainly introduces 2 modules: typical route construction module and passenger aircraft market demands analysis module. the flowchart is shown in Fig. 3.

Fig. 3 is flowchart of civil aircraft market demands analysis. firstly, take flights data in specific region as sample, then initial the optimal match between aircraft types and typical routes out of all routes, obtaining the initial analysis results of market demands; lastly, conduct market adaptability analysis based on the initial analys is results, and then the ultimate market demands results can be acquired.

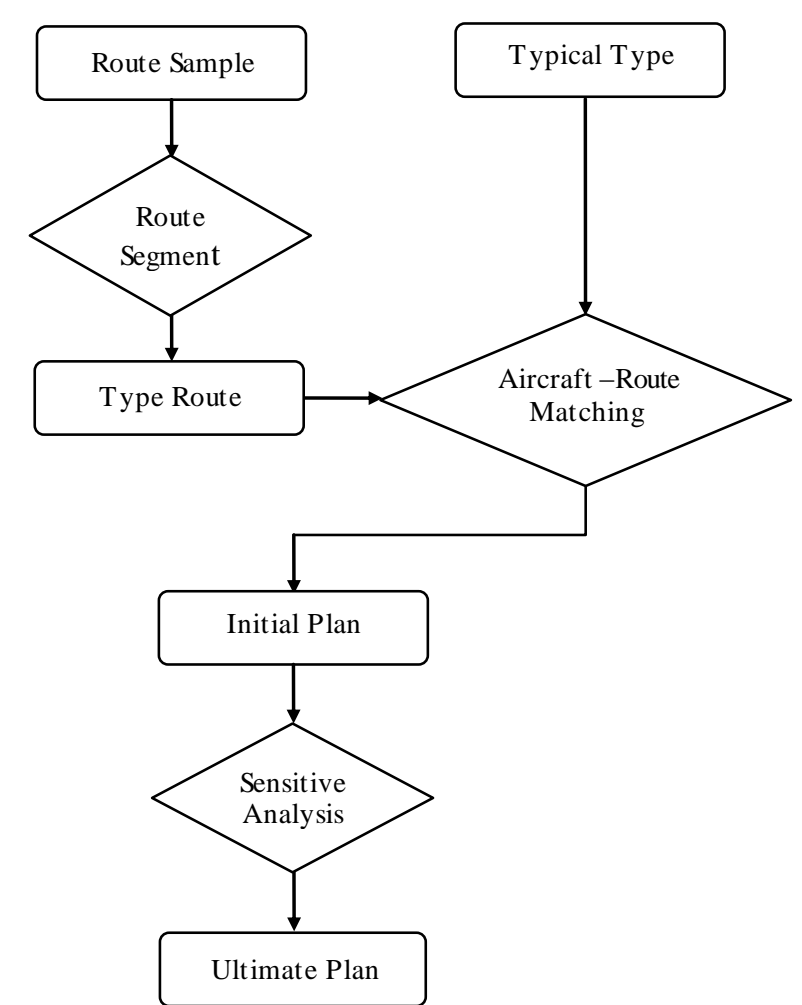

Figure 3. Flow chart of passenger aircraft market demand analysis

\section{A. Typical routes construction}

Typical routes is defined as classify the routes in specific region by relevant criteria, and then select the center of each classification, that center is called typical flights. Typical routes is used to represent route market segments so as to reduce the simulating scale of route transportation capacity optimal allocation.

\section{1) Route market segment}

This sub-module is developed under route market segmenting methods mentioned in 2.1, used for segmenting specific regional route market. since there might be numerous routes in specific region, it is complex and inefficient to solve directly under Visual Studio. Therefore, excellent calculating tools like Matlab can be adapted to segment route market. construct the market segmenting planning library in MATLAB, use Matlab COM Builder to create COM components, generate a selfextracting installation document; then run this selfextracting installation document, generate dll files, and then use these dll files in Visual Studio 2010, an accurate and rapid demands analysis can be realized. the detailed process is as follows:

-1) Input "mex-setup"in Matlab 7.7 command window, compiling environment will be shown, select VC6.0;

-2) Input "deploytool"in command window, and Deployment toolwindow will be opened.

- 3) Select "New Deployment Project" to open a window, then select "MATLAB Builder NE"-".NET Component", click "OK" to finish the creation of new compiling project;

-4) Add the edited flight market segment document m; 
- 5) Click "Build the project" to generate dll files.

-6) Use the dll files in Visual Studio 2010.

2) Typical route identification

Select the center of each cluster as typical route. the minimum passenger capacity of a typical route is the sum of the minimum passenger capacity of its market segment (see (10)).passenger load factor of "X-type" aircraft in each "typical" route is the ratio between historical passenger capacity and annual seat numbers provided (see (11)). The maximum flight frequency of "typical" flight is the sum of all flight frequency in the market segment it belongs to (see (12)). Block time of "X-type" aircraft in each flights is the weighted average of the block time of each type and level aircrafts of each flights in the market segment (see (13)). The flight frequency of "typical" flight is the sum of all flights frequency in the market segment it belongs to (see (14)).

$$
\begin{aligned}
& D \min _{j}^{\prime}=\sum 1\left\{c^{(i)}=j\right\} D \min _{i}, \quad \forall j=1,2, \cdots, k \\
& L F_{l j}^{\prime}=\frac{\sum_{i=1}^{m} 1\left\{c^{(i)}=j\right\} D_{l i}}{\sum_{i=1}^{m} 1\left\{c^{(i)}=j\right\} \operatorname{Cap}_{l i}}, \quad \forall l=1,2, \cdots, n \\
& F_{j}^{\prime}=\sum_{i=1}^{m} 1\left\{c^{(i)}=j\right\} F_{i}, \quad \forall j=1,2, \cdots, k \\
& t e_{l j}^{\prime}=\frac{\sum_{i=1}^{m} 1\left\{c^{(i)}=j\right\} t e_{l i}}{\sum_{i=1}^{m} 1\left\{c^{(i)}=j\right\} F_{l i}}, \quad \forall l=1,2, \cdots, n \\
& F_{j}=\sum_{i=1}^{m} 1\left\{c^{(i)}=j\right\} F_{i}, \quad \forall j=1,2, \cdots, k
\end{aligned}
$$

\section{B. Cvil aircraft market demands analysis}

The function of this sub-module is to analyze civil aircraft market demands in specific region under the market demands analysis plan library.

Thanks to the application of typical route to represent all routes in the market segment, the scale of the calculation is enabled to compact. It is feasible to use traditional integer programming methods to construct an analys is plan library in MATLAB, then generate dll files which can be referenced later in Visual Studio 2010. This process assures the accurate and rapid demands analysis. The whole calculating process is accomplished on the server, therefore, even if the calculation is complex, the speed of user's computer will not affect the calculating speed. the results of flight market demands analys is will be indicated on the following interface shown in Fig. 4.

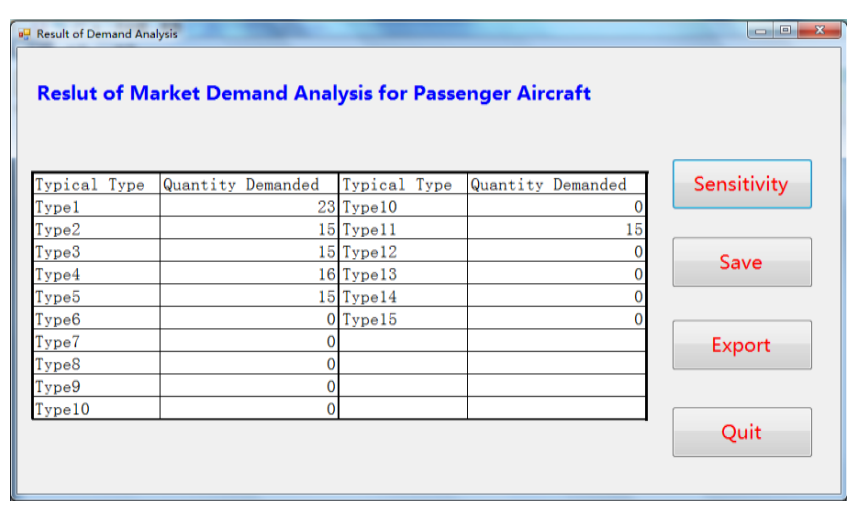

Figure 4. Result interface of market demand analysis

\section{Sensitivityanalysis lysis}

The main function of sensitivity analysis is to test the impact of market demands fluctuation on civil aircraft demands. With the predicted passenger number fixed, the fleet optimal allocation plan will be analy zed respectively when the market demands fluctuate in a plus or minus $40 \%$ range.

\section{The ultimate results}

Unser modifies the initial plan according to the predicted results and sensitivity analysis results. the ultimate plan can either be saved to database, or be exported to EXCEL.

\section{CONCLUSIONS}

This paper constructs a model for passenger aircraft market demand. for calculating efficiency consideration, the flights are classified into several classification. each classification is represented by a "typical" flight. By realizing the match between typical flights and aircraft types, the demand for each aircraft types can be defined. Furthermore, on the basis of the above theory, a passenger aircraft market demand analysis system is developed. Combining with .net framework, this system developed Web application program, Web services and MATLAB. It is a easy-to-learn and compact-to-install system. users can adjust according to one's own experiences and sensitivity analysis.

\section{ACKNOWLEDGMENT}

This work was financially supported by the National Science Foundation of China (61179074) and Civil Aviation Science and Technology of China (MHRD20130303).

\section{REFERENCES}

[1] Sun Hong. National Natural Science Foundation of China Project Concluding report : 《Airline Fleet Planning Measure Based on Fleet Assignment 》(60776820) [R]. 2010. (In Chinese)

[2] Embraer.2010-2029 Chinese Regional Maket Forcast[R].2010

[3] Airbus.2009-2028Global Maket Forcast[R].2009.

[4] Boeing.2009-2028Current Maket Outlook[R].2009.

[5] Sun H, Zhang P W, Wang Y. Fleet Planning Approach Based on Route Fleet Assignment Optimizing [J]. Journal of Southwest Jiaotong University, 2010, 45(1):111-115. (In Chinese)

[6] Zhu Jinfu. Air Transportation Programming [M]. Xi' an:Northwestern Polytechnical University, 2008:268-294. (In Chinese)

[7] Jani Kilpi.Fleet composition of commercial jet aircraft 1952-2005: Developments in uniformity and scale[J].Journal of Air Transport Management, Vol.13 (2) ,2007: 81-89.

[8] Armacost, A.P., Barnhart, C., Ware, K., Wilson, A. UPS optimizes its air net work[J].Interfaces,2004.Vol.34: 15-25.

[9] Bahram A, Garland C, Kambiz R. The effects of market structure and technology on airline fleet composition after deregulation [J]. Review of Industrial Organization, 1999, 15(1): 77-88.

[10] Listes O, Dekker R. A scenario aggregation based approach for determining a robust airline fleet composition for dynamic capacity allocation [J]. Transportation Science, 2005, 39(3): 367-382.

[11] Wang Y, Sun H. Heurist algorithm of fleet planning based on airline fleet assignment [J]. Systems Engineering-Theory \& Practice. 2011, 31(2): 371-378. (In Chinese)

[12] Wang Y, Sun H. Research on the algorithm of one class fixed job scheduling problem [J]. Journal of University of Electronic Science 
and Technology of China (Social Science Edition). 2010, 12(3): 19-22. (In Chinese)
[13] Zhang Peiwen, Sun Hong,Wang Yu. Study on Market Demand Analysis Method for Passenger Aircraft[J]. Railway Transport and Economy,2015,71(1):18-21.(In Chinese) 